\title{
Searching for Bioethical Prescriptions in a Moral Lab
}

\author{
Marta Soniewicka (Jagiellonian University, Cracow)
}

Review of the book by F. M. Kamm (2013). Bioethical Prescriptions: To Create, End, Choose, and Improve Lives. Oxford: Oxford University Press, pp. 599

\section{Introduction}

The book Bioethical Prescriptions collects previously published essays and transforms them into a coherent, enormous piece of work addressing the broad spectrum of the main bioethical concerns. The collection was preceded by Kamm's similar endeavor which resulted in producing a volume in the field of ethics entitled Intricate Ethics. Rights, Responsibilities, and Permissible Harm (2007). Both of the volumes complement each other, yet can be read separately. The collection starts with the essays on death and dying (passive and active euthanasia, suicide and assisted suicide, definition of death, terminating life-sustaining treatment, conceptual framework referring to the end of life, the philosophical analysis of the connection between the meaning of life and the meaning of death), followed by essays concerning early life (reproduction, abortion, research on human embryos) and some on genetic and other enhancements (including reflections on justice towards future generations in distribution of life and genes, and on cloning). The fourth part addresses the problem of the allocation of scarce resources (including the consideration of such notions as health and equality, as well as challenging the problem of discrimination against the disabled in rationing scarce resources). The last part of the book elucidates some methodological issues (such as the difference between the two models of argumentations: the theoretical top-down and the practical bottom-up; the relation between theory and practice in bioethics, the role of philosophy in bioethical committees, as well as the connection between self-inquiry and justifying one's own moral judgments). Reading this book requires considerable powers of concentration through all 600 pages at one sitting, otherwise one would be easily lost in the labyrinths of profound argumentation. Kamm presents a detailed, comprehensive overview and an insightful critical analysis of some major arguments developed by other authors in the above-mentioned subjects which makes this book a very attractive kind of compendium of bioethical debates, a must-read for anyone concerned with bioethics.

To produce a brief review of this book I have to be selective. I shall address some general methodological questions which underline the entire 
book, as well as the core of her argumentation for the non-consequentialist, rights-based approach. Finally, I discuss the chapter concerned with the famous essay by Leo Tolstoy entitled The Death of Ivan Ilych which is different from the other chapters in the book.

\section{Methodological issues}

For all those readers for whom Bioethical Prescriptions are their first encounter with Kamm's philosophical investigations, I would suggest beginning this book from the final part which provides some impressions about her methodology. The title of the book reflects Kamm's approach to moral philosophy. In the Introduction she explains that "This book's title plays with the concept of a doctor's prescriptions only with regard to bioethical content" (p. xi). By comparing philosophers to doctors, Kamm does not aim at providing simple solutions, moral directives or recommendations of certain polices. She is fully aware of the fact that ethical problems are complex and intricate (p. 580; she previously claimed this point in the afore-mentioned book entitled Intricate Ethics). Yet she believes that a fair and deep examination of an issue, which is the aim of moral philosophy, can make the moral superiority of one sort of action or one type of policy clear. What Kamm wants to prescribe to all who are concerned with bioethical questions is not a certain solution defended by her, but rather her way of coming to that conclusion by taking into account all factors conducive to certain decisions or actions. She critically analyzes different ethical arguments and tests them against her moral intuitions.

\subsection{Trolleyology}

The characteristic feature of Kamm's philosophical analysis is expressed in generating counterfactual dilemmas in order to produce 'case-based judgments' (pp. 551-564). Her imagination in this matter is impressive. She calls this the Method of Hypothetical Cases (p. 579). According to her method, one should not ignore any case-based judgments even if they seem counterintuitive or are in contradiction with plausible principles; one let to be surprised by oneself and try to analyze all one's own judgments and justify their grounds (Kamm 2007, $5)$.

Kamm is famous of constructing an enormous number of variants of the so-called Trolley Problem to test a certain conjecture about the grounds of certain moral intuitions (p. 578; cf. Kamm 2007). She applies a scientific method of experimental induction to philosophical analysis of moral problems, according to which one removes one factor after another in the constructed moral experiments to discover which one motivated people to their decisions. Kamm describes her method by comparison to scientific experiments in the following words: 
Scientists use experiments in which they can change one variable at a time, holding everything else constant, in order to see if that variable is crucial to an explanation of a phenomenon. The Method of Hypothetical Cases is the use of thought experiments, which often seem bizarre because we can imagine a factor being present or absent, holding constant all other factors, though this could not happen in reality. But just as artificially controlled conditions in a lab can lead to results that are applicable to real life, the results of artificial thought experiments might help us explain intuitive responses in 'messier' cases closer to real life or in real life (p. 579).

A mere explanation of people's behavior would satisfy psychologists but not philosophers, in particular such a sophisticated one as Kamm, who aim rather at finding the justification of behavior. Understanding morality is different from reconstructing the motivations underlying moral judgments; to understand any normative judgment one has to understand the reasons that people take to justify their behavior. Kamm claims that the Method of Hypothetical Cases helps to realize this aim and that it prevents her analysis of intuitive judgments from an objection of confabulation given by Kahnemann (p. 579 ff). Kamm believes that there are principles underlying our moral judgments ('implicit morality') which we can discover and make conscious by testing our moral judgments in thought experiments. I agree with Kamm that our moral reasoning cannot be identified with confabulations similar to those that are produced by a hypnotized person who tries to explain her unconscious behavior. Yet I have doubts if this could be proven by scientific-like thought experiments. By constructing a thought experiment one develops an artificial state of affairs which would be extremely unlikely to happen in the real world in order to isolate the factors that produce a certain moral decision and to specify which factor is the most significant. My concern is that our moral life is too complex to be so easily reconstructed and grasped in experiments held in a kind of 'moral lab'. Even if people try to challenge the Trolley Problem in the classroom, it does not mirror how they would and should behave if they faced a similar moral dilemma in a real-world situation. Our moral intuitions which reflect our experience and work well in our everyday life may turn out to be totally misleading when applied to an exotic dilemma constructed at the desk of a philosopher. And this could be a reason not to give so much respect to our intuitions when they are generated artificially in lab conditions which cannot be treated seriously as the independent moral authority in real life. When thought experiments leave the classroom and start infiltrating political and legal debates, as was the case with the ticking time bomb scenario which was used to justify torture, they could cause a moral catastrophe.

Behavioral psychologists have conducted many investigations in heuristics in order to prove that people's intuitive responses to unfamiliar scenarios are usually burdened with logical errors. Thus, one may claim that moral thought experiments are aimed at elucidating our moral inconsequence 
and to force us to reject our intuitions if we find no good reasons to justify them, as Kamm argues. But I think that applying this kind of scientific approach to the domain of moral values is unconvincing. Testing even the most improbable hypotheses can prove to be useful in gaining theoretical knowledge, but does not help much in improving our moral knowledge as to which is the most practical one (aimed at right actions). Aristotle claimed that his ethical "inquiry does not aim at theoretical knowledge like the others (for we are inquiring not in order to know what virtue is, but in order to become good, since otherwise our inquiry would have been of no use), we must examine the nature of action, namely how we ought to do them..." If critical analysis of moral judgments is aimed at unifying our experience with our system of values, then it raises doubts if the trolleyology to which Kamm is so committed, is an appropriate method to realize this aim. Trolleyology rests on an assumption of the atomization of morality, i.e., possibility of isolating deeds, motives, and reasons from the entire human life and from who people are and want to be. This seems to be inconsistent with our everyday experience in which our actions and decisions are deeply rooted in the dynamic complexity of our life (this point can be vividly illustrated by the famous case of "Jim and Indians" made by Bernard Williams in which he used an argument from moral integrity). Lab conditions successfully prevent us from considering such problems with reference to our life, personality and relations. Most of the people who face a counterfactual moral dilemma think rather about solving an abstract problem which is more like a riddle, than about becoming oneself. Trolleyology gives us the impression that moral dilemmas are like chess, where one seeks to find the best strategy.

\subsection{Between foxes and hedgehogs}

Kamm argues for the superiority of case-based reasoning over theory in solving ethical problems. She challenges Dworkin's top-down reasoning which comes from "deeper principles and theoretical justification for those principles" (p. 551). Working on an assumption that our theoretical moral competence is limited (The Principle of Imperfect Competence), she prefers bottom-up reasoning with the use of analogies. Invoking Isaiah Berlin's distinction between hedgehogs (unifiers) and foxes (multipliers), Dworkin considered himself as a hedgehog: "the fox knows many things, but the hedgehog knows one big thing. Value is one big thing." He defended a unified theory of value according to which there are no irreconcilable conflicts among genuine values. He believed that moral truth is within our grasp and this implies that, even in hard cases, there is one objectively right answer supported by the best reasons and arguments we have and referring to "what the best case shows".

Foxes like Berlin, who did not share the French Enlightenment's optimism that all values and rational goals can be ultimately humanized, reject the ideal of monism and defend pluralism of values, where conflicts of values 
are inevitable. He claimed that there are some ultimate values which are incommensurable, i.e., there is no common moral currency in terms of which their conflict could be resolved with no loss of value. It not only contests utilitarian thinking with its common moral currency but also the Kantian or Lockean tradition in moral philosophy, where basic rights and liberties are placed beyond the conflict. In value-conflict situations, a pragmatic compromise is possible but it is not a stable one. And for many people this is the reason that the debates over such intricate questions as abortion, stem-cell research, genetic selection etc., remain open and unsettled ones.

Kamm is neither a hedgehog nor a fox, but a mixture of them. Like foxes, she assumes that there are many conflicting values (p. 539), yet she believes like a hedgehog that we can solve all conflicts of values by applying a special procedure or an external independent point of view which guarantees the verification of values (p. 539; pp. 571-572). Instead of 'tragic pluralism', she assumes the Rawlsian idea of 'reasonable pluralism' in which 'reflective equilibrium' and 'moralized compromise' are possible (pp. 527-545), even in the most intricate issues as abortion, euthanasia etc. One may have some reservations as to whether this kind of optimism is justified, but it would be a question not to Kamm alone, but rather to the whole philosophical tradition to which she aspires. Following Rawls she assumes that there are "some publicly accepted values (e.g., those inherent to constitutional democracy) that all should be expected to share as justifications for polices" (p. 572). This is the line of reasoning that Kamm follows in her attempt to justify (amongst others) the right to abortion (Creation and Abortion - summarized in chapter 12). People do not agree about abortion since they do not share an understanding of the normative status of fetus or embryo - their values are rooted in different philosophical and religious doctrines.

Kamm approaches the problem from a different angle, considering a dilemma based on values publicly shared in a liberal state to pose a question about the limits of the sacrifice of our freedom to which we could be forced in order to save somebody's life. She works on the Violinist Case which was invented by Thomson in order to show that even if we assumed that a fetus were a person, there could be no moral duty to give birth to a conceived child. The conclusion was made by analogy to the case of a person who was kidnapped in order to use her body for nine months to keep a famous violinist alive who would otherwise die. As Kamm summarizes: "the violinist's right to life does not imply a right to use someone else's body even in order to save his life. (...) the person to whom he is attached is the victim of an injustice" (p. 184). Kamm constructs different variations of the Violinist Case. She does it using detailed, multi-step nonconsequentialist reasoning, constructing arguments that justify the permissibility of killing in order to protect the supporter's bodily integrity. 
Her approach to the problem of abortion was contrasted with the approach presented by Dworkin - it was said that Kamm's argumentation is more lawyer-like, though she is a philosopher, while Dworkin's book was more philosophical although he was a lawyer (p. 553). Dworkin's main thesis was that the question of abortion cannot be solved without addressing the problem of intrinsic values (such as life) while Kamm's approach was focused on rights and interests in reproduction which is more characteristic for legal reasoning. Dworkin believes that rights are rooted in our system of values. Thus, according to him one cannot use an analogy without introducing theory, since "an analogy is a way of stating a conclusion, not a way of reaching one" (p. 552). Kamm disagrees with this, claiming that 'analogy can be a way of reaching a conclusion' (p. 554). But when we carefully consider the analogies that Kamm produces in their multiplied variations, it seems quite obvious that they are constructed to defend or object to certain arguments which are based on some values. The use of analogies is similar to the use of metaphors, their essence "is understanding and experiencing one kind of thing in terms of another." No metaphor and no analogy exhausts the meaning of an abstract problem, but rather turns our attention to one of the characteristics we want to emphasize. And this is exactly what the Violinist Case does - it emphasizes the problem of rights and interests, glossing over other significances.

\subsection{Analogies and metaphors}

In her further chapters on enhancement, when Kamm criticizes Shiffrin's claims on reproductive harm based on the Gold Cube Case, she admits that not all analogies are appropriate for reproductive dilemmas since a fetus is not a person (so the arguments about harm to persons does not apply; p. 273). But many of the analogies that Kamm uses also seem flawed. For instance, while challenging Sandel's argument from hubris against genetic enhancement, Kamm constructs an analogy of an artist who is seeking for mastery which does not undermine the value of his art. This analogy seems inadequate since Sandel's claim is based on an understanding of parent-child relationship as different from an instrumental relationship between a designer and her design. Another example: Kamm argues that if people do not see anything wrong in praying for the best for their children (assuming that their prayers could work), they should also accept providing their progeny with the best possible genetic makeup to achieve the same aim (p. 345). This analogy emphasizes that in both cases children would be provided with some external help to achieve a 'happy life'. But it obscures the significant difference in both approaches, where praying parents have trust in an omniscient God who is the only one who knows what would be good for every human being. In contrast, the designing parents assume that they know what would be the best for their progeny-a highly controversial claim. 


\section{Reproductive Choices: Enhancement and the Ethic of Creating New People}

From the reasoning on the permissibility of abortion, Kamm turns to developing her 'ethic of creating new people' (p. $197 \mathrm{ff}$ ). She believes that creators owe to their creatures more than not having a life which is not better than non-existence (something more than not to be harmed), and this may require some sacrifice. Kamm argues for the so-called 'minima' which every new person has a right to have guaranteed by being born (p. $267 \mathrm{ff}$; it is not permissible according to Kamm to create people if their lives do not meet the minima since it would violate their rights). She applies a veil of ignorance to justify her claim on what a creator owes to its creature, taking into account the interests of future people (pp. 198-199; pp. 253-290). I do not aim at challenging her sophisticated arguments here which would require a separate article (Kamm herself addresses many different arguments and objections given by Dworkin, MacMahan, Shiffrin, Buchanan et. al., in the chapters on early life and on enhancement). I would like only to make a general remark on Kamm's approach to such issues as reproduction. As Nagel emphasizes, the principles of justice are applied to institutions, not to private decisions and choices: "Rawls's egalitarianism does not apply either to individual morality or to individual outcomes within the bounds of an egalitarian state." Therefore, the Just Creation Question (p. $255 \mathrm{ff}$ ) posed by Kamm seems misleading, at least when considered in terms of social fairness and entitlements. Utilitarianism and egalitarianism provide the principles for the fair distribution of welfare or resources, but they both fail to provide any intuitive principles for reproductive decisions. It is very hard to maintain that in such an intimate sphere, parental decisions should be governed by any universal, purely rational ideals. Reproductive choices are not a matter of the fair distribution of life or genetic properties, but rather a private endeavor resulting from meaningful relationships. The question of whether one should be engaged in reproduction in certain ways and at certain risks can be separated from the question about fairness and the outcomes produced by these decisions for a society since the former depends on how we understand ourselves and our relationships.

In reply to Dworkin's objection that the permissibility of killing a fetus that is a person would imply the permissibility of infanticide and the abandonment of children by their parents, Kamm distinguishes between being voluntary creators and parents (p. 223). She claims that a true parental relation develops when a baby is born which may result in some special obligations. Challenging Sandel's objection against ex ante enhancement based on the idea of balance between accepting and transforming love, Kamm claims that love must always be to a particular child and does not cover a relation with a fetus (p. 342). This distinction between creators and parents seems very artificial 
and counterintuitive. Perhaps only in some rare cases of surrogacy, one could imagine a separation of these roles.

In her considerations on genetic selection and enhancement, Kamm claims that a duty to prevent the birth of a disabled child (by abortion or embryo selection) cannot be objected to as discriminatory to disabled people (p. $277 \mathrm{ff}$ ). She argues that people are discriminated against when they are deprived of their opportunities but non-existing persons have no opportunities yet. A duty to prevent the birth of a disabled child is based on the view that impairment is bad and this view cannot be objected to as prejudice, otherwise surgery would be considered as wrong, as Kamm claims (p. 279). One may object to this reasoning in a twofold fashion. Firstly, there is a difference between treatment in which impairment or a disease can be removed so as a particular person could benefit from it; and abortion or selection by which instead of preventing an impairment, one prevents the birth of impaired child. Secondly, one cannot discriminate against those who were never born, but one can discriminate against those who are already living with disabilities by arguing that their disabilities justify the decision of preventing the birth of a person.

Making moral choices behind a veil of ignorance or in a moral lab of the type profoundly constructed by Kamm requires prospective parents to take their reproductive decisions as being detached from what for them matters in such choices, namely the understanding of their practices and the values they promote. Morality concerns the question of how to live well and how to treat other people and it should provide a "connection between a sense of who we are, what kind of being, and the way we live". The rights-based approach followed by Kamm considers life and death as mere facts, neglecting our understanding of the significances, such as death, birth, sexuality and their mysteriousness which have a profound impact on "our capacity to live [and to choose] well" as Diamond claims. Since they cannot be captured in any rational normative system of ethics, "the desire for systematized impartiality can denature moral thought."

\section{The Worth of Life and the Necessity of Death}

In her analysis of Tolstoy's famous essay on the death of Ivan Ilych, Kamm provides an insightful interpretation according to which Ivan's inability to accept the fact of his death was caused by his inability to find a justification for his own (nasty and wasteful) life (p. 13 ff). Ivan lived a trivial, pleasant life in which he never faced the truth of his life which prevented him also from facing the truth of his death (Kamm calls it aptly the "double resistance to the truth" p. 13). Kamm argues that 'The temptation is to read 'Ivan Ilych' as though the prospect of death is necessary to make one think of the worth of one's life and the possibility (or necessity) of death is what makes it necessary to live a good 
life" (p. 10). In agony, Ivan comes to a revealing conclusion that he has not lived as he should have and Kamm points out this revelation as a turning point (p. 5). It transforms his character and brings about the rectification of his life by accepting the truth and a new set of values according to which his life was a failure (p. 16). Kamm does not specify what it could mean to live as one ought to live, claiming that it depends on "the intrinsic, nonconseqentialist value of being a certain sort of person" (p. 20). She believes that some people may live as they should have and concludes that such people do not need the kind of revelation experienced by Ivan in his agony.

There is something important missing in this interpretation. Tolstoy was not only a writer but also a mystic philosopher to whom people used to go on pilgrimages to, as one would to a prophet. He excommunicated himself from the Russian Orthodox Church because of disagreements about the interpretation of the Bible and his reservations to the Church which he described in the autobiographical book entitled A Confession (1880). The novel "The Death of Ivan Illych" (1886) was published shortly after his spiritual transformation and was profoundly affected by his experience which cannot be neglected in the interpretation. I think that Tolstoy's novel addresses the problem of the experience of life and death on multiple levels: a) conventional (describing how people are embarrassed by the fact of death which they treat as an unpleasant incident interfering in their life and frightening them so they make a conventional deception as if death did not concern them); b) moral (when Ivan judges what he did wrong in his life); c) existential (when Ivan experiences being between two voids of nonbeing; at this level he experiences the senselessness of life and the reality and loneliness of death, i.e., Heideggerian being towards death); religious-mystical (when he experiences love of his son and of his servant Gerasim, can see the light, and reconciles himself with God).

Kamm claims that in the last few seconds of his life Ivan had an insight of how to live (Kamm 2007, p. 21). I am not sure he did. Let me invoke one of the last crucial passages of the novel which elucidates the kind of salvation which Ivan experienced then:

His hand fell on the boy's head, and the boy caught it, pressed it to his lips, and began to cry. At that very moment Ivan Ilych fell through and caught sight of the light, and it was revealed to him that though his life had not been what it should have been, this could still be rectified. He asked himself, »What is the right thing? « and grew still, listening. (...) He tried to add, »Forgive me, " but said »Forego" and waved his hand, knowing that $\mathrm{He}$ whose understanding mattered would understand...

Ivan suffers when he finds out that his entire life was "not real at all, but a terrible and huge deception which had hidden both life and death". But the truth about life and death is not a moral truth, but rather a metaphysical one. 
The afore-mentioned passage of the novel shows that the revelation he experienced provided an insight that the truth about good life escapes human understanding. When Ivan poses the question about what is the right thing, silence is the only answer. But it does not matter anymore when he realizes that there is a transcendental being who understands everything. This sheds new light on the senselessness of life (it remains for him impossible to understand what it is all about but there is Somebody who understands: "He whose understanding mattered would understand") and makes him possible to transcendent death:

"Where is it? What death?" There was no fear because there was no death. In place of death there was light. »So that's what it is!« he suddenly exclaimed aloud. "What joy!" ... . "Death is finished," he said to himself. "It is no more!"

A positive image of Gerasim, who is a healthy, honest peasant boy, reflects Tolstoy's fascination with Russian peasantry which he idealized and admired for their common wisdom and instinctive faith. Gerasim is one of the few people in the novel who seems to be aware of one's own mortality, as well as of the fact that Ivan is dying; he is neither terrified by death nor deceived by the absence of death; his reaction is simple: "»It's God will. We shall all come to it some day «"

\section{Concluding Remarks}

Kamm's approach to philosophy may be shared by some readers and contested by others. Yet her impressive, monumental work deserves attention. It can be used as a guidebook to bioethical arguments, as well as a textbook and source of numerous moral dilemmas. By following Kamm's argumentation, one can acquaint oneself with the rigorous and detailed analytical thinking which she presents on a masterly level in the reviewed book.

\section{References}

Annas, G. 2010. Worst Case Bioethics. Death, Disaster, and Public Health. Oxford: Oxford University Press.

Aristotle. 1999. Nicomachean Ehics. Trans. W. D. Ross. Kitchener: Batoche Books.

Berlin, I. 1969. Four Essays on Liberty. Oxford: Oxford University Press.

Diamond, C. 1990. "How Many Legs." In R. Gaita (ed.), Value and Understanding: Essays for Peter Winch. New York: Routledge: 149-178.

Dworkin, R. 1973. Life's Dominion. An Argument about Abortion, Euthanasia, and Individual Freedom. New York: Vintage Books. 
Dworkin, R. 2011. Justice for Hedgehogs. Cambridge Mass., London: The Belknap Press of Harvard University Press.

Kamm, F. M. 2007. Intricate Ethics. Rights, Responsibilities, and Permissible Harm. Oxford: Oxford University Press.

Kahneman, D. \& Tversky, A. 1984. "Choices, Values and Frames." American Psychologist 39(4): 341-350.

Lakoff, G. \& Johnson, M. 2010. Metafory w naszym życiu (Metaphors we Live By). Warszawa: Aletheia.

Nagel, T. 2005. "The Problem of Global Justice". Philosophy and Public Affairs 33: 113-147.

Parens, E. \& Asch, A. 2003. "Disability Rights Critique of Prenatal Genetic testing: Reflections and Recommendations." Mental Retardation and Developmental Disabilities Research Reviews 9: 40-47.

Tolstoy, L. 2013. The Death of Ivan Ilych. Trans. L. \& A. Maude. ReaderWorks. An Electronic Classics Series Publication.

Tversky, A. \& Kahneman, D. 1974. "Judgment Under Uncertainty: Heuristics and Biases". Science 185(4157): 1124-31.

Williams, B. 1973. "Utilitarianism: For and Against." In J. J. C. Smart, (ed.), An Outline of a System of Utilitarian Ethics. Cambridge: Cambridge University Press. 


\title{
Marta Soniewicka (Cracow)
}

\section{Searching for Bioethical Prescriptions in a Moral Lab}

\begin{abstract}
The paper reviews the book written by F.M. Kamm, entitled Bioethical Prescriptions: To Create, End, Choose, and Improve Lives (published in Oxford: Oxford University Press in 2013, pp. 599). Kamm is one of the most prominent analytical philosophers in moral philosophy, known from such works as Intricate Ethics (2007). She defends the rights-based approach to ethics and is also famous from constructing multilayered moral dilemmas. The review poses methodological questions, of whether scientificlike thought experiments performed in a moral lab, and the Method of Hypothetical Cases are able to transform our ethical dilemmas and provide any solutions. In the final part of the review, the first chapter of the book on Tolstoy's essay (The Death of Ivan Ilych) is discussed in more detail.
\end{abstract}

Keywords: Bioethics, trolley problem, enhancement, reproduction, Tolstoy, death.

Ethics in Progress (ISSN 2084-9257). Vol. 6 (2015). No. 1, pp. 199-210.

doi: 10.14746/eip.2015.1.14a 